\title{
High amniotic fluid erythropoietin levels are associated with an increased frequency of fetal and neonatal morbidity in Type 1 diabetic pregnancies
}

\author{
K. Teramo ${ }^{1}$ M. A. Kari ${ }^{2}$ M. Eronen ${ }^{2}$ H. Markkanen ${ }^{2}$ - V. Hiilesmaa ${ }^{1}$ \\ ${ }^{1}$ Department of Obstetrics and Gynaecology, University Central Hospital, Helsinki, Finland \\ ${ }^{2}$ Hospital for Children and Adolescents, University Central Hospital, Helsinki, Finland \\ ${ }^{3}$ Clinical Laboratory Diagnostics, University Central Hospital, Helsinki, Finland
}

\section{Abstract}

Aims/hypothesis. In this study we investigated whether chronic fetal hypoxia, as indicated by amniotic fluid erythropoietin levels, is associated with perinatal morbidity in Type 1 diabetic pregnancies.

Methods. A total of 331 women with Type 1 diabetes had at least one childbirth between 1995 and 2000. The amniotic fluid erythropoietin concentration was measured in 156 diabetic singleton pregnancies at a median time of 1 day before Caesarean section without labour contractions and in 19 healthy control subjects at Caesarean section.

Results. The median amniotic fluid erythropoietin level was $14.0 \mathrm{mU} / \mathrm{ml}$ (range 2.0-1975.0) in diabetic pregnancies and $6.3 \mathrm{mU} / \mathrm{ml}$ (range 1.7-13.7) in controls $(p<0.0001)$. Of the 156 diabetic patients, $21(13.5 \%)$ had amniotic fluid erythropoietin levels higher than $63.0 \mathrm{mU} / \mathrm{ml}$. Amniotic fluid erythropoietin levels correlated negatively with umbilical artery $\mathrm{pH}(r=$ $-0.49, p<0.0001)$ and $\mathrm{pO}_{2}(r=-0.62, p<0.0001)$ at birth and neonatal lowest blood glucose level $(r=-0.47$, $p<0.0001)$. Positive correlations were found between amniotic fluid erythropoietin levels and umbilical artery $\mathrm{pCO}_{2}(r=0.49, p<0.0001)$ and last maternal $\mathrm{HbA}_{1} \mathrm{c}$
( $r=0.43, p<0.0001)$. Furthermore, a U-shaped correlation was demonstrated between amniotic fluid erythropoietin levels and birthweight $z$ score $(z$ score below -0.6 SD units: $r=-0.63, p=0.0007 ; z$ score above +1.0 SD units: $r=0.32, p=0.0014)$. Neonatal hypoglycaemia, hypertrophic cardiomyopathy and admission to the neonatal intensive care unit occurred significantly more often in cases with high amniotic fluid erythropoietin levels $(>63.0 \mathrm{mU} / \mathrm{ml})$ than in those with normal levels. Multivariate logistic regression analysis revealed that amniotic fluid erythropoietin was the only variable independently related to low umbilical artery $\mathrm{pH}(<7.21 ; p<0.0001)$ and neonatal hypoglycaemia $(p=0.002)$. Low umbilical artery $\mathrm{pO}_{2}(<15.0 \mathrm{~mm} \mathrm{Hg})$ was explained by amniotic fluid erythropoietin $(p<0.0001)$ and birthweight $z$ score $(p=0.004)$.

Conclusions/interpretation. Antenatal high amniotic fluid erythropoietin levels can identify Type 1 diabetic pregnancies at increased risk of severe perinatal complications.

Keywords Amniotic fluid - Amniocentesis . Erythropoietin · Fetus · Hypoxia · Macrosomia Neonatal complications · Pregnancy · Type 1 diabetes mellitus
Received: 24 March 2004 / Accepted: 23 June 2004

Published online: 22 October 2004

C Springer-Verlag 2004

K. Teramo (®)

Department of Obstetrics and Gynaecology,

University Central Hospital, Box 140, 00290 Helsinki, Finland

E-mail: kari.teramo@huch.fi

Tel.: +358-94711, Fax: +358-947174801

Abbreviations: EPO, erythropoietin

\section{Introduction}

Abnormal fetal heart rate, cord blood acidosis and low Apgar scores occur more often in diabetic pregnancies than in non-diabetic pregnancies, indicating an increased risk of intrauterine hypoxia [1,2]. Fetal plasma and amniotic fluid erythropoietin (EPO) levels are also frequently elevated, suggesting an increased incidence of chronic fetal hypoxia in pregnancies complicated by diabetes $[3,4]$. This is further supported by 
the polycythaemia and increased nucleated red cells often observed in the fetuses and newborn infants of diabetic women $[5,6]$. The depletion of iron stores in fetal liver, brain and heart in stillborn fetuses of diabetic mothers suggests that chronic fetal hypoxia precedes fetal death in the majority of cases [7].

Amniotic fluid EPO levels are strongly correlated with umbilical plasma EPO concentrations in both normal and abnormal pregnancies, including diabetic pregnancies, before the onset of labour $[4,8,9,10]$. Since EPO does not cross the placenta [11], elevated amniotic fluid EPO levels are indicative of subchronic or chronic fetal hypoxia. Accordingly, both fetal plasma and amniotic fluid EPO levels are negatively correlated with umbilical arterial $\mathrm{pH}, \mathrm{pO}_{2}$ and base excess $[4,10,12,13]$.

This study aimed to investigate the occurrence of chronic fetal hypoxia, as reflected by amniotic fluid EPO, and whether this is associated with fetal and neonatal complications in pregnancies complicated by Type 1 diabetes.

\section{Subjects and methods}

Diabetic subjects. Between 1 September 1995 and 31 December 2000, a total of 331 women with Type 1 diabetes had at least one childbirth at the Department of Obstetrics and Gynaecology, University Central Hospital, Helsinki. Since labour contractions can increase fetal EPO levels [14], only diabetic women with a singleton pregnancy delivered by Caesarean section before the onset of labour were included in the study. When a woman had more than one childbirth during the study period, one pregnancy was chosen at random to be included in the study. A total of 234 (70.7\%) Type 1 diabetic women were delivered by Caesarean section before the onset of labour. Of these 234 women, 156 had amniotic fluid sampled by amniocentesis either within 2 days before delivery or at delivery by Caesarean section. In one Type 1 diabetic woman with a vaginal delivery, amniotic fluid was sampled for EPO measurement 1 day after fetal death. Thus, a total of 157 diabetic women were included in this study. The local ethics committee approved the study protocol and subjects gave their informed consent before the samples of amniotic fluid were taken.

Relative birthweight adjusted for gestational age and sex was expressed as a $z$ score using a Finnish reference population [15]. Macrosomia was defined as a birthweight more than 2 SD units above the mean of the reference population. Neonatal hypoglycaemia was defined as a neonatal capillary whole blood glucose value below $2.0 \mathrm{mmol} / \mathrm{l}$ more than $6 \mathrm{~h}$ after delivery. Respiratory distress syndrome was defined as respirator or continuous positive airway pressure treatment for more than $24 \mathrm{~h}$ with or without surfactant treatment. Respirator treatment for meconium aspiration $(n=1)$ and for apnoea episodes $(n=2)$ were not classed as respiratory distress syndrome. Echocardiography was performed in 38 newborn infants during the first week of life by a paediatric cardiologist or a neonatologist. Hypertrophic cardiomyopathy was defined as interventricular septal thickness more than $2 \mathrm{SD}$ units above the normal mean [16]. Neonatal hyperbilirubinaemia was defined as the presence of an indication to treat with blue light.

Control subjects. Nineteen healthy, non-smoking women delivered by elective Caesarean section with an uneventful single- ton pregnancy and a healthy newborn infant were chosen as control subjects. The indications for elective Caesarean sections were repeat Caesarean section or breech presentation. An amniotic fluid sample and an umbilical vein sample were obtained at delivery for the determination of EPO levels.

Sampling of amniotic fluid. At this hospital, amniotic fluid is obtained routinely by amniocentesis for fetal lung maturity evaluation in Type 1 diabetic pregnancies at around 37 weeks of gestation or earlier when indicated. The amniocenteses were performed by senior staff obstetricians under ultrasound guidance. The median time interval between the last amniotic fluid EPO sample and delivery was 1 day (range 0-2 days). The EPO level from the last amniotic fluid sample before or at delivery was used for the analyses.

Sampling of umbilical cord blood. The umbilical cord was doubly clamped before the infant's first cry, and umbilical artery blood was sampled into a heparinised syringe. Samples were kept on wet ice and analysed within 15 min of delivery for $\mathrm{pH}$, acid-base and haemoglobin measurements using the Corning pH/Blood Gas Analyzer (Model 178; Corning, N.Y., USA). In 22 diabetic women, umbilical venous blood was centrifuged and the plasma separated for EPO analysis in addition to the amniotic fluid sample obtained at delivery by Caesarean section.

Measurement of erythropoietin. Up to 31 July 1998, erythropoietin levels were measured in duplicate in amniotic fluid and cord plasma by RIA (EPO-Trac, Incstar, Stillwater, Minn., USA), after which time a chemiluminescent immunological method (Immulite EPO Assay; Diagnostic Products, Los Angeles, Calif., USA) was used. To allow comparison, both methods were used to analyse EPO concentrations in amniotic fluid samples from 80 high-risk patients and 18 healthy controls. The results obtained were similar for the two methods and so all measurements were used in the final analyses. The assays were standardised according to the World Health Organization's Second International Reference Preparation for EPO.

Measurement of HbAlc. In the Type I diabetic women, $\mathrm{HbA}_{1} \mathrm{c}$ levels in blood samples taken at each outpatient visit (2- to 4-week intervals) were assessed by HPLC (Diamat; Bio-Rad Laboratories, Hercules, Calif., USA). The mean $\mathrm{HbA}_{1} \mathrm{c}$ level in non-diabetic, healthy, non-pregnant adults as determined using this method is $4.93 \%$ (SD $0.32 \%$ ). The last $\mathrm{HbA}_{1} \mathrm{c}$ concentration obtained before delivery was used in the analyses. $\mathrm{HbA}_{1} \mathrm{c}$ levels were not measured in the healthy, non-diabetic control subjects.

Statistical analyses. Comparisons of normally distributed continuous variables were performed using the Student's $t$ test or one-way ANOVA with the Bonferroni correction. EPO values had a skewed distribution and were logarithmically transformed before analyses. Variables that were not normally distributed were analysed by the Mann-Whitney U-test or the Kruskal-Wallis test. Categorical variables were analysed by the chi square test. Linear regression was used to examine associations between continuous study variables. Multiple logistic regression was used to assess the independent effects of clinical variables and EPO levels on umbilical artery low $\mathrm{pH}$ and low $\mathrm{pO}_{2}$ at birth and fetal macrosomia and neonatal hypoglycaemia. Receiver operating characteristic (ROC) curves were constructed to determine the sensitivity and specificity of amniotic fluid EPO cut-off values in predicting low $\mathrm{pH}$ and low $\mathrm{pO}_{2}$ in arterial cord blood at birth, neonatal hypoglycaemia and cardiomyopathy. All tests were two-sided, and $p$ values less than 0.05 were considered statistically significant. Statistical calculations were performed using the NCSS 2000 software program (NCSS, Kaysville, Utah, USA). 


\section{Results}

Type 1 diabetic women were younger, somewhat more obese and more often nulliparous than the control subjects (Table 1). Of the 234 diabetic women delivered by Caesarean section, 156 (66.7\%) women had at least one amniotic fluid sample taken for EPO measurement within 2 days before delivery. Elective Caesarean section was performed in $129(82.7 \%)$ of the 156 diabetic women after fetal lung maturity had been confirmed by the ratio of lecithin : sphingomyelin and phosphatidyl glycerol measurements in the amniotic fluid (Table 1). Newborn infants of Type 1 diabetic women with nephropathy $(n=16)$ had a shorter gestational age and a lower birthweight $z$ score than those born to other Type 1 diabetic women (data not shown).

All 156 newborn infants delivered by Caesarean section in this study were born alive. The newborn infants were put under observation in the neonatal intermediate care unit for at least $12-24 \mathrm{~h}$ or were transferred to the neonatal intensive care unit. None of the newborn infants died during the neonatal period. Intraventricular haemorrhage (grade 2) occurred in one $(0.6 \%)$ newborn infant, and respiratory distress occurred in 15 (9.6\%). Nineteen newborn infants $(12.2 \%)$ were treated in the neonatal intensive care unit. Neonatal hypertrophic cardiomyopathy was observed in ten $(6.4 \%)$ newborn infants. None of the newborn infants had outflow tract obstruction.

The median amniotic fluid EPO level was significantly higher $(p<0.0001)$ in diabetic pregnancies (14.0 $\mathrm{mU} / \mathrm{ml}$, range $2.0-1975, n=155)$ than in the control pregnancies $(6.3 \mathrm{mU} / \mathrm{ml}$, range $1.7-13.7, n=19)$. One case with an extremely high amniotic fluid EPO level $(9300 \mathrm{mU} / \mathrm{ml})$ was excluded from the analyses as a clear outlier and because of unknown developmental problems in the newborn infant (Figs. 1, 2, 3, 4).

Logarithmically transformed amniotic fluid EPO levels correlated with umbilical venous plasma EPO levels obtained simultaneously at delivery in diabetic pregnancies $(y=-0.31+0.85 x ; r=0.89, p<0.0001, n=22)$. Amniotic fluid EPO levels correlated negatively with umbilical artery $\mathrm{pH}(r=-0.49, p<0.0001), \mathrm{pO}_{2}(r=$ $-0.62, p<0.0001$; Fig. 1$)$ and base excess $(r=-0.21$, $p=0.008$ ) at birth, and with the lowest blood glucose level more than $6 \mathrm{~h}$ after delivery of the newborn infant ( $r=-0.47, p<0.0001$; Fig. 2). A positive correla-

Fig. 1. Logarithmically transformed last amniotic EPO concentration obtained 1 day (median) before delivery correlated negatively with umbilical artery $\mathrm{pH}(y=92.4-12.4 x, r=-0.49$, $p<0.0001, n=153)$ (a) and with umbilical artery $\mathrm{pO}_{2}(y=2661.2$ $\left.4570.0 x+2886.2 x^{2}-780.0 x^{3}+75.6 x^{4}, r=-0.62, p<0.0001, n=152\right)$ (b) and positively with umbilical artery $\mathrm{pCO}_{2}$ at birth $(y=-1.28+$ $0.48 x, r=0.49, p<0.0001, n=152)(\mathbf{c})$ in Type 1 diabetic pregnancies. The arrow indicates the case that was excluded as a clear outlier and because of unknown developmental problems in the newborn infant. $1 \mathrm{kPa}=7.5 \mathrm{~mm} \mathrm{Hg}$ tion was found between amniotic fluid EPO and umbilical artery $\mathrm{pCO}_{2}(r=0.49, p<0.0001$; Fig. 1c). A U-shaped correlation was demonstrated between amniotic fluid EPO and birthweight $z$ score (Fig. 3). The correlation was negative when the birthweight
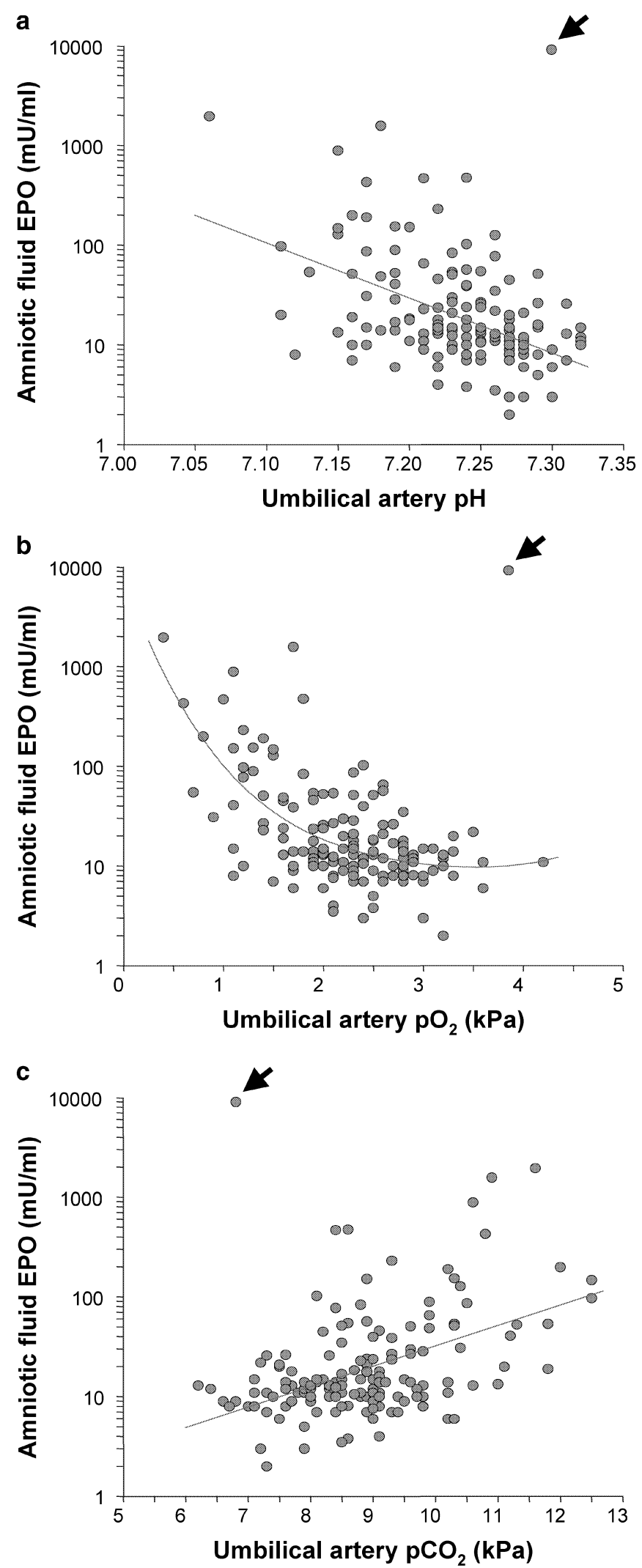
Table 1. Characteristics of Type 1 diabetic women and healthy controls

\begin{tabular}{lccc}
\hline Characteristic & Control pregnancies $(n=19)$ & Type 1 diabetic pregnancies $(n=156)$ & $p$ value \\
\hline Maternal age (years) & $33.1 \pm 4.7$ & $30.3 \pm 4.9$ & 0.02 \\
Nulliparous & $4(21.1)$ & $77(49.4)$ & $24.6 \pm 4.0[147]$ \\
Pre-pregnancy BMI $\left(\mathrm{kg} / \mathrm{m}^{2}\right)$ & $22.4 \pm 1.7$ & $31(19.9)$ & 0.02 \\
Smoker & $0(0)$ & $36.5 \pm 1.6$ & $<0.0001$ \\
Gestation (weeks) & $39.0 \pm 0.5$ & $129(82.7)$ & $61(39.1)$ \\
Elective Caesarean section & $19(100)$ & $6.8(5.0-10.9)$ & $14.0(2.0-9300)$ \\
Fetal macrosomia & $0(0)$ & $28.6(11.3-9252)[22]$ & $<0.0001$ \\
Last HbA 1 c $(\%)$ & NA & $6.3(1.7-13.7)$ & 0.006 \\
Amniotic fluid EPO $(\mathrm{mU} / \mathrm{ml})$ & $16.4(6.7-35.8)$ & & \\
Plasma EPO $(\mathrm{mU} / \mathrm{ml})$ & & & \\
\hline
\end{tabular}

Values are means $\pm \mathrm{SD}$, medians (ranges) or $n(\%)$. All women had a singleton childbirth by Caesarean section before the onset of labour contractions. Fetal macrosomia was defined as a birthweight $z$ score higher than 2.0 SD units. NA, not available; [ ], number of subjects, if different

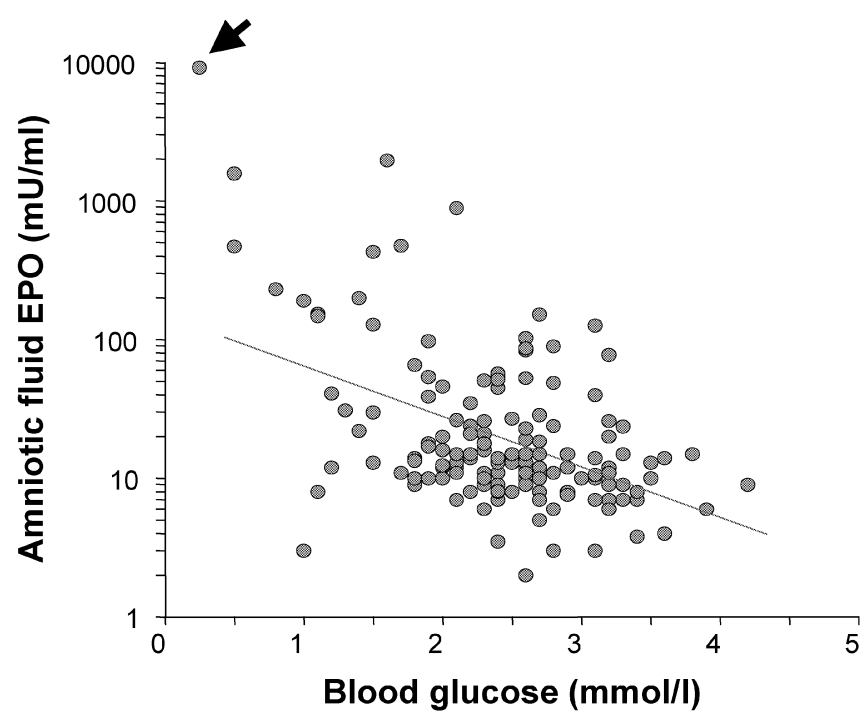

Fig. 2. Logarithmically transformed last amniotic fluid EPO concentration obtained 1 day (median) before delivery correlated negatively with lowest blood glucose concentration of the newborn infant obtained more than $6 \mathrm{~h}$ after birth $(y=4.98-$ $0.83 \mathrm{x}, r=-0.47, p<0.0001, n=155)$ in Type 1 diabetic pregnancies. The arrow indicates the case that was excluded (see Fig. 1a-c) $z$ score was below -0.6 SD units $(r=-0.63, p=0.0007$; $n=25)$ and positive when it was above +1.0 SD units ( $r=0.32, p=0.0014, n=97)$; it was not significant between -0.6 and +1.0 SD units $(r=0.04, n=33)$. Amniotic fluid EPO correlated positively with the last maternal $\mathrm{HbA}_{1} \mathrm{c}$ before delivery $(r=0.43, p<0.0001$; Fig. 4). Amniotic fluid EPO levels did not correlate with umbilical vein haemoglobin concentration at birth.

Amniotic fluid EPO levels above $63.0 \mathrm{mU} / \mathrm{ml}$ (more than ten times higher than the median of the healthy controls) were considered to indicate chronic fetal hypoxia. Amniotic fluid EPO levels were elevat-

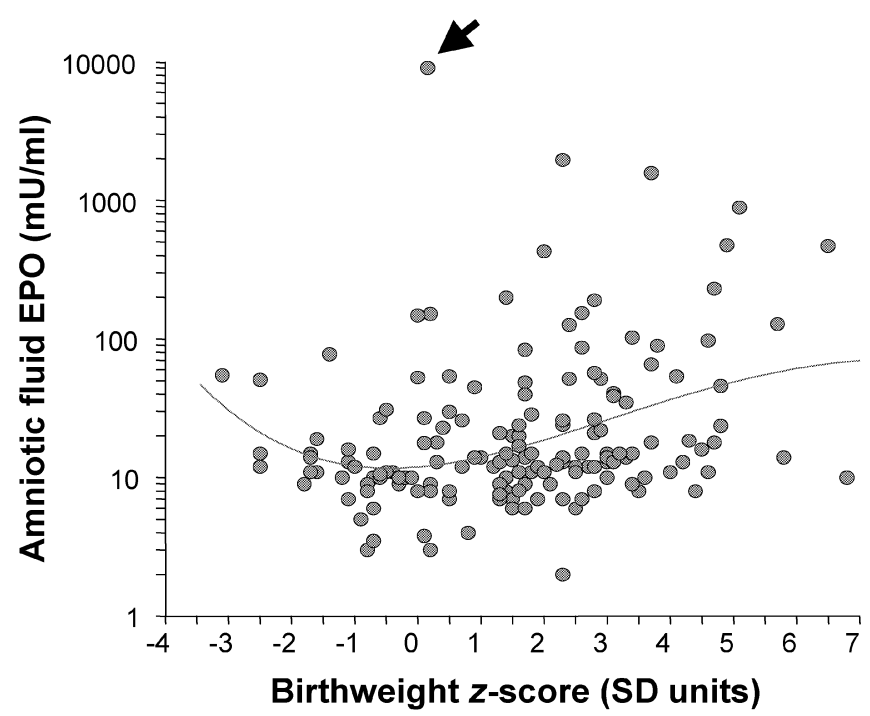

Fig. 3. Logarithmically transformed last amniotic fluid EPO concentration obtained 1 day (median) before delivery was correlated in a U-shaped fashion with birthweight $z$ score (4th degree polynomial regression line is shown) in Type 1 diabetic pregnancies. The correlation was negative when the birthweight $z$ score was below $-0.6 \mathrm{SD}$ units $(r=-0.63, p=0.0007, n=25)$, not significant between -0.6 and +1.0 SD units $(r=0.04, n=33)$ and positive above $+1.0 \mathrm{SD}$ units $(r=0.32, p=0.0014 ; n=97)$. The arrow indicates the case that was excluded (see Fig. 1a-c)

ed to values above $63.0 \mathrm{mU} / \mathrm{ml}$ in $22(14.1 \%)$ of the 156 Type 1 diabetic women.

The diabetic patients were divided into groups according to the last amniotic fluid EPO level (low EPO group $<13.8 \mathrm{mU} / \mathrm{ml}$, intermediate EPO group $13.8-63.0 \mathrm{mU} / \mathrm{ml}$, high EPO group $>63.0 \mathrm{mU} / \mathrm{ml}$ ). The cut-off value for the low EPO group was chosen based on the upper range for the healthy control subjects $(13.7 \mathrm{mU} / \mathrm{ml})$. The diabetic mothers in the high EPO group were younger and had higher $\mathrm{HbA}_{1} \mathrm{c}$ levels than the diabetic mothers in the other two groups (Table 2). Maternal BMI before pregnancy did not differ between the three groups. Newborn infants 
Table 2. Maternal and fetal data (median and range or frequencies) in 155 Type 1 diabetic women grouped according to last amniotic fluid EPO level

\begin{tabular}{|c|c|c|c|c|}
\hline \multirow[t]{2}{*}{ Characteristic } & \multicolumn{3}{|l|}{ Type 1 diabetic pregnancies } & \multirow[t]{2}{*}{$p$ value } \\
\hline & $\begin{array}{l}\text { Low EPO group } \\
(n=76)\end{array}$ & $\begin{array}{l}\text { Intermediate EPO group } \\
(n=58)\end{array}$ & $\begin{array}{l}\text { High EPO group } \\
(n=21)\end{array}$ & \\
\hline $\mathrm{AF} \operatorname{EPO}(\mathrm{mU} / \mathrm{ml})$ & $10.0(2.0$ to 13.4$)$ & $21.0(14.0$ to 57.0$)$ & $153.0(66.0$ to 1975$)$ & \\
\hline Maternal age (years) & $31(18$ to 41$)$ & $30(22$ to 40$)$ & $27 \mathrm{a}$ (21 to 38$)$ & 0.02 \\
\hline $\operatorname{BMI}\left(\mathrm{kg} / \mathrm{m}^{2}\right)$ & $23.3(19.0$ to 37.0$)[71]$ & 24.1 (19.0 to 43.7$)$ [55] & $24.9(21.6$ to 32.7$)$ & NS \\
\hline Birthweight $(\mathrm{g})$ & $3522(1690$ to 5250$)$ & $3760(840$ to 5350$)$ & $4230^{\text {a }}(1280$ to 5240$)$ & 0.03 \\
\hline Birthweight $z$ score & $1.3(-2.5$ to 6.8$)$ & $1.7(-3.1$ to 5.8$)$ & $2.8^{\mathrm{b}}(-1.4$ to 6.5$)$ & 0.0005 \\
\hline UA pH & $7.26(7.12$ to 7.32$)[74]$ & $7.24(7.11$ to 7.32$)$ & $7.19^{\mathrm{b}}(7.06$ to 7.26$)$ & $<0.0001$ \\
\hline $\mathrm{UA} \mathrm{pO}_{2}(\mathrm{kPa})(1 \mathrm{kPa}=7.5 \mathrm{~mm} \mathrm{Hg})$ & $2.4(1.1$ to 4.2$)[74]$ & $2.2(0.7$ to 3.5$)$ & $1.3^{\mathrm{b}}(0.4$ to 2.6$)[20]$ & $<0.0001$ \\
\hline $\mathrm{UA} \mathrm{pCO}_{2}(\mathrm{kPa})(1 \mathrm{kPa}=7.5 \mathrm{~mm} \mathrm{Hg})$ & 8.5 (6.2 to 11.0$)[74]$ & $8.9(7.1$ to 11.8$)$ & $10.3^{\mathrm{b}}(8.1$ to 12.5$)[20]$ & $<0.0001$ \\
\hline UA base excess $(\mathrm{mmol} / \mathrm{l})$ & $-1.4(-8.3$ to 4.4$)[74]$ & $-1.6(-5.6$ to 2.2$)[57]$ & $-2.5^{\mathrm{a}}(-9.6$ to 0.0$)$ & $<0.0001$ \\
\hline
\end{tabular}

Values are medians (ranges) or $n(\%)$. One case with an extremely high amniotic fluid EPO level $(9300 \mathrm{mU} / \mathrm{ml})$ was excluded from the high EPO group because of unknown developmental problems of the newborn infant (see also Figs. 1-4). a $p$ value significantly different vs low EPO group by one-way

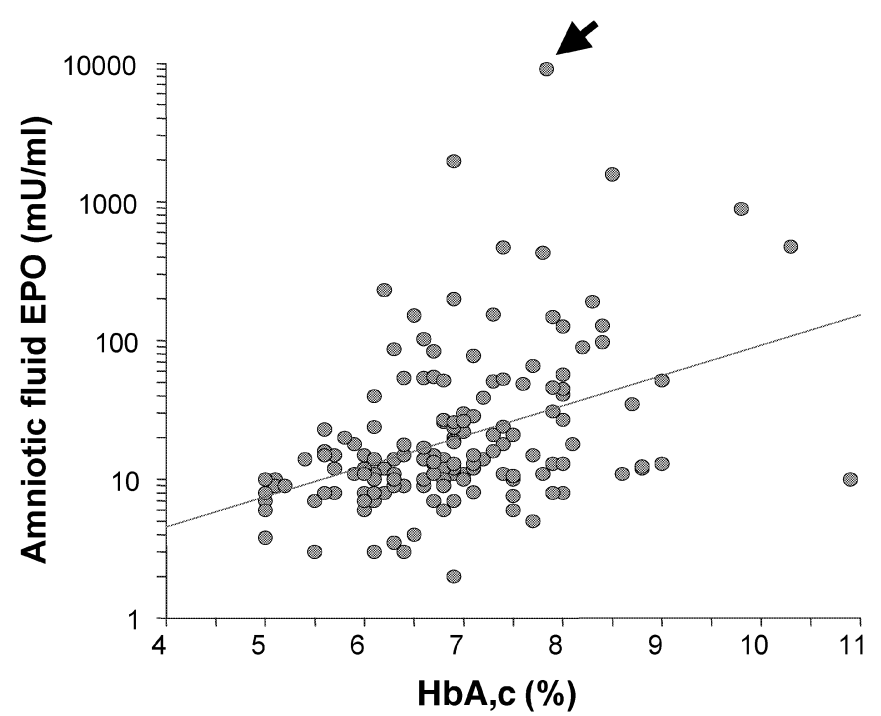

Fig. 4. Last amniotic fluid logarithmic EPO concentration obtained 1 day (median) before delivery correlated positively with maternal $\mathrm{HbA}_{1} \mathrm{c}$ obtained 8 days (median) before delivery $(y=-0.50+0.50 x, r=0.43, p<0.00001, n=155)$ in Type 1 diabetic pregnancies. The arrow indicates the case that was excluded (see Fig. 1a-c)

in the high EPO group were more macrosomic, more acidotic and had lower $\mathrm{pO}_{2}$ levels than those in the intermediate or high EPO groups (Table 2). Gestational age at birth, number of newborn infants delivered before the completion of 35 weeks of gestation, 1-min Apgar scores and umbilical venous haemoglobin concentration did not differ between the three groups (Tables 2 and 3).
ANOVA; ${ }^{\mathrm{b}} p$ value significantly different vs low and intermediate EPO groups by one-way ANOVA. AF, amniotic fluid; UA, umbilical artery; UV, umbilical vein; [ ], number of subjects, if different

Neonatal hypoglycaemia (blood glucose $<2.0 \mathrm{mmol} / \mathrm{l}$ more than $6 \mathrm{~h}$ after delivery), admission to the neonatal intensive care unit, cardiomyopathy and hyperbilirubinaemia occurred significantly more often in the high EPO group than in the low EPO group (Table 3). The median amniotic fluid EPO level in cases with cardiomyopathy (113.5 $\mathrm{mU} / \mathrm{ml}$, range 10.0-1594.0, $n=10$ ) was significantly higher $(p=0.005)$ than in cases without cardiomyopathy $(13.0 \mathrm{mU} / \mathrm{ml}, 2.0-1975.0, n=145)$.

Figure 5 shows the individual amniotic fluid EPO levels of the diabetic women in the high EPO group. There were six diabetic women with at least two amniotic fluid EPO measurements. All had an emergency Caesarean section for fetal distress, and in all six cases the amniotic fluid EPO level was observed to increase exponentially. In three of the six cases, amniotic fluid EPO levels were not known prior to delivery and thus did not influence clinical decisions. In the other three cases, amniotic fluid EPO levels were known before delivery and thus could have influenced the decision to perform an emergency Caesarean section. All six cases had abnormal fetal heart rate recordings with late decelerations on the day of delivery. In the stillbirth case of a White's class $\mathrm{C}$ diabetic patient, the amniotic fluid EPO level obtained 1 day after the fetal death was $2290 \mathrm{mU} / \mathrm{ml}$ (Fig. 5).

Figure 6 shows the receiver operating characteristic (ROC) curves of amniotic fluid EPO concentrations for predicting low $\mathrm{pH}(<7.21)$ and low $\mathrm{pO}_{2}(<2.0 \mathrm{kPa}$ or $<15.0 \mathrm{~mm} \mathrm{Hg}$ ) in umbilical artery blood at birth, and low plasma glucose $(<2.0 \mathrm{mmol} / \mathrm{l})$ and hypertrophic cardiomyopathy in the newborn infant. An amniotic fluid EPO cut-off value of $17.6 \mathrm{mU} / \mathrm{ml}$ had $66.7 \%$ 


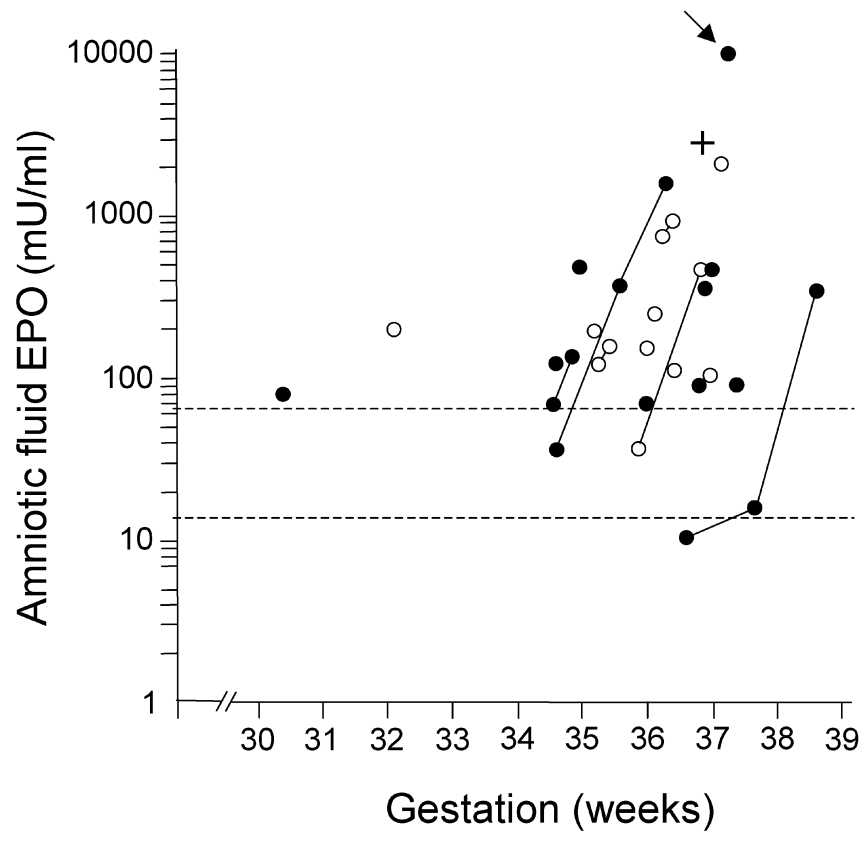

Fig. 5. Logarithmically transformed amniotic fluid EPO concentration and gestational age at the time of amniotic fluid sampling in the 23 Type 1 diabetic women in the high EPO group $(\mathrm{EPO}>63.0 \mathrm{mU} / \mathrm{ml}$ ). The lower dotted horizontal line represents the upper range $(13.7 \mathrm{mU} / \mathrm{ml})$ of amniotic fluid EPO levels of the control subjects and the upper horizontal dotted line represents ten times the median value of the controls $(63.0 \mathrm{mU} / \mathrm{ml})$. The case indicated by the arrow was excluded from the analyses as a clear outlier and because of unknown developmental problems in the newborn infant. The cross indicates the amniotic fluid EPO value $(2290 \mathrm{mU} / \mathrm{ml})$ obtained 1 day after fetal death; this value was not included in the analyses. In six cases, two or three amniotic fluid samples were obtained (connected by continuous lines). All six cases with sharply increasing EPO levels had an emergency Caesarean section for fetal distress. Closed circles, cases in which the EPO level was not known prior to delivery; open circles, cases in which the EPO level was known prior to delivery sensitivity and $70.1 \%$ specificity for predicting low $\mathrm{pH}(<7.21)$ and $68.1 \%$ sensitivity and $75.2 \%$ specificity for predicting low $\mathrm{pO}_{2}(<2.0 \mathrm{kPa}$ or $<15.0 \mathrm{~mm} \mathrm{Hg})$ at birth. The corresponding sensitivity and specificity levels of this cut-off value for macrosomia (birthweight $z$ score $>2$ SD units) were $50.8 \%$ and $70.6 \%$ respectively. An amniotic fluid EPO cut-off value of $26.3 \mathrm{mU} / \mathrm{ml}$ had $58.1 \%$ sensitivity and $79.0 \%$ specificity for predicting low blood glucose levels $(<2.0 \mathrm{mmol} / \mathrm{l})$ and $60.0 \%$ sensitivity and $73.8 \%$ specificity for predicting cardiomyopathy in the newborn infant (Fig. 6).

Multivariate logistic regression analysis was used to examine the effects of maternal age, maternal BMI, gestational age at birth, birthweight $z$ score, last amniotic fluid EPO level and last maternal $\mathrm{HbA}_{1} \mathrm{c}$ level obtained before delivery on low umbilical artery $\mathrm{pH}$ and $\mathrm{pO}_{2}$ at birth and low plasma glucose level of the newborn infant. After adjusting for these variables, amniotic fluid EPO was the only one to remain independently related to low $\mathrm{pH}(p<0.0001)$ and neonatal hypoglycaemia $(p=0.002)$. Low $\mathrm{pO}_{2}$ was explained by amniotic fluid EPO $(p<0.0001)$ and birthweight $z$ score $(p=0.004)$. Fetal macrosomia was explained by last maternal $\mathrm{HbA}_{1} \mathrm{c}(p=0.008)$ and maternal $\mathrm{BMI}$ $(p=0.04)$.

\section{Discussion}

We observed that elevated EPO levels in antenatally obtained amniotic fluid samples were significantly associated with adverse fetal and neonatal outcome in Type 1 diabetic pregnancies. The associations between high amniotic fluid EPO levels and neonatal hypoglycaemia, hypertrophic cardiomyopathy and increased admission to the neonatal intensive care unit are new observations. The U-shaped correlation between amniotic fluid EPO levels and relative birthweight is also a new observation, and suggests that the fetuses of

Table 3. Number of preterm deliveries before 35 weeks of gestation and number of neonatal complications in 155 Type 1 diabetic women grouped according to last amniotic fluid EPO level

\begin{tabular}{|c|c|c|c|c|}
\hline \multirow[t]{2}{*}{ Characteristic } & \multicolumn{3}{|c|}{ Type 1 diabetic women } & \multirow[t]{2}{*}{$p$ value ${ }^{a}$} \\
\hline & $\begin{array}{l}\text { Low EPO group } \\
(n=76)\end{array}$ & $\begin{array}{l}\text { Intermediate EPO } \\
\text { group }(n=58)\end{array}$ & $\begin{array}{l}\text { High EPO group } \\
(n=21)\end{array}$ & \\
\hline Amniotic fluid EPO (mU/ml) & $10.0(2.0-13.4)$ & $21.0(14.0-57.0)$ & $153.0(66.0-1975)$ & \\
\hline Gestational age $<35$ weeks & $6(7.9)$ & $4(6.9)$ & $4(19.0)$ & NS \\
\hline Hypoglycaemia (plasma glucose $<2.0 \mathrm{mmol} / \mathrm{l}$ ) & $9(11.8)$ & $9(15.5)$ & $13(61.9)$ & $<0.0001$ \\
\hline Hyperblirubinaemia & $28(40.0)[70]$ & $21(38.2)[55]$ & $17(81.0)$ & 0.002 \\
\hline
\end{tabular}

Values are medians (ranges) or $n(\%)$. One case with an extremely high amniotic fluid EPO level $(9300 \mathrm{mU} / \mathrm{ml})$ was excluded from the high EPO group because of unknown devel- opmental problems of the newborn infant (see also Figs. 1-4). a chi square test. NICU, neonatal intensive care unit; [ ], number of subjects, if different 

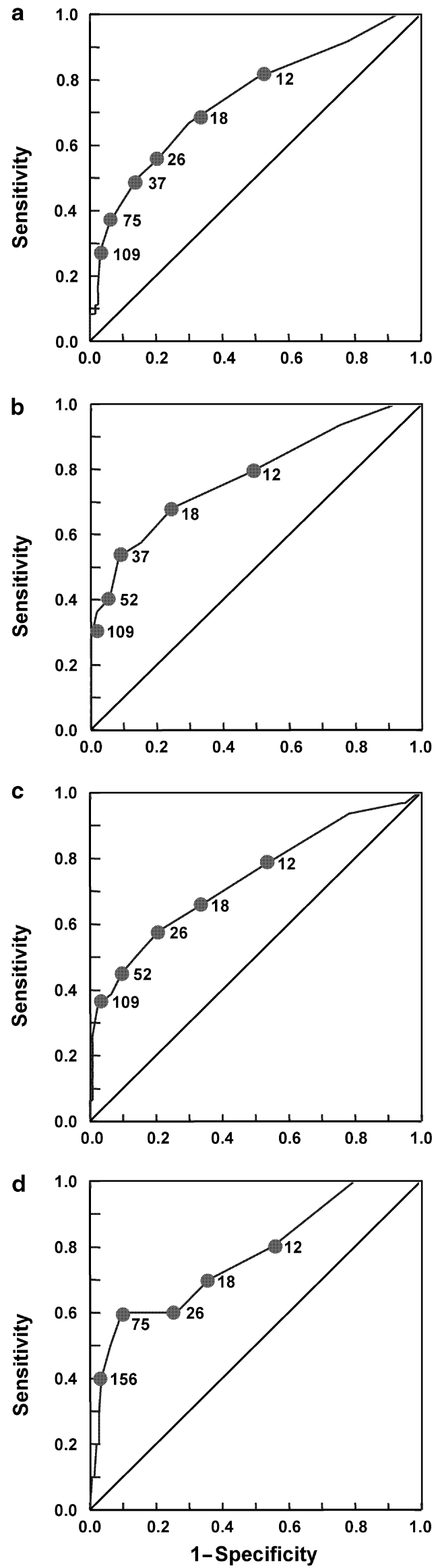

mothers with Type 1 diabetes are actually growth restricted when their birthweight $z$ score is below -0.6 SD units. Thus, both growth-restricted fetuses and macrosomic fetuses are at increased risk of intrauterine hypoxia in Type 1 diabetic pregnancies.

Strengths and weaknesses of the study. This is the largest study to date to investigate the associations between amniotic fluid EPO levels and fetal and neonatal outcome in Type 1 diabetic pregnancies. Since our hospital is the only referral centre for pregnant Type 1 diabetic women in Southern Finland (District of Uusimaa, catchment population 1.6 million), and the pregnancies were studied consecutively over a 5-year period, the study is also population based. Repeated amniotic fluid sampling revealed that once EPO levels start to increase above the normal range, they do so exponentially in most cases.

One of the limitations of this study is that the controls could not be matched for gestational age and timing of amniotic fluid sampling. It is also important to point out that the patients included in the study had a better fetal and neonatal outcome than those not included in the study because of lack of amniotic fluid sampling. This is due to the fact that the main reason for not obtaining an amniotic fluid sample was the occurrence of signs of fetal distress. Another limitation of this study is that fetal blood flow measurements were not taken systematically, thus precluding the comparison of amniotic fluid EPO levels and fetal blood flow indices.

Other studies. Although the exact mechanisms of fetal hypoxia in diabetic pregnancies are not fully understood, several factors may compromise fetal oxygen supply [17]. Experimental studies in fetal sheep have shown that both fetal hyperglycaemia and fetal hyperinsulinaemia can independently cause fetal hypoxaemia $[18,19,20]$. Maternal $\mathrm{HbA}_{1} \mathrm{c}$ levels measured during the last month of pregnancy are correlated with fetal plasma EPO levels at birth [21], suggesting that maternal antepartum hyperglycaemia, and hence fetal hyperglycaemia, is associated with fetal hypoxaemia. Similarly, amniotic fluid EPO levels correlated with the last maternal $\mathrm{HbA}_{1} \mathrm{c}$ level obtained before birth in this study. Furthermore, it has been shown that amniotic fluid insulin levels are correlated with fetal plasma erythropoietin levels, independently of the maternal glycaemic level [21]. Thus, both fetal hypergly-

Fig. 6. The receiver operating characteristic (ROC) curves of amniotic fluid EPO concentrations obtained 1 day (median) before delivery by Caesarean section before the onset of labour for predicting low $\mathrm{pH}(<7.21)$ (a) and low $\mathrm{pO}_{2}(<2.0 \mathrm{kPa}$ or $<15.0 \mathrm{~mm} \mathrm{Hg}$ ) (b) of umbilical artery blood at birth, and low blood glucose $(<2.0 \mathrm{mmol} / \mathrm{l})(\mathbf{c})$ and hypertrophic cardiomyopathy (d) in the newborn infant. The numbers next to the ROC curve points are EPO levels expressed in $\mathrm{mU} / \mathrm{ml}$ 
caemia and fetal hyperinsulinaemia may cause fetal chronic hypoxaemia and eventually fetal death in humans. In the present study, multiple regression analysis showed that an elevated amniotic fluid EPO level was the most important variable associated with umbilical artery acidosis and hypoxaemia at birth. The amniotic fluid EPO concentration was very high in the stillbirth case in which amniotic fluid was obtained 1 day after fetal death (Fig. 5). This also supports the view that fetal demise in diabetic pregnancy is preceded by a period of chronic fetal hypoxaemia.

Prior to the introduction of modern electronic fetal surveillance, the fetal death rate in diabetic pregnancies increased during the last weeks of pregnancy [22]. Although overall glycaemic control has improved among Type 1 diabetics over the last 20 years, it is unlikely that the trend of increasing fetal distress and fetal deaths during the last weeks of pregnancy has totally disappeared. Unexplained fetal deaths still occur [23], and perinatal mortality is still clearly increased in these pregnancies [24]. The fetuses of mothers with poor glycaemic control during the last weeks of pregnancy are particularly at risk of fetal hypoxaemia $[21,24]$. In the present study we showed that, in addition to poor glycaemic control, fetal growth restriction and fetal macrosomia both correlated with increased levels of amniotic fluid EPO levels and hence with chronic fetal hypoxaemia. Strategies to prevent stillbirths in diabetic pregnancies include fetal surveillance by fetal heart rate and ultrasonographic monitoring during the last weeks of pregnancy [25]. However, there is no established best method of monitoring fetal well-being in diabetic pregnancies.

Our results confirm and extend previous observations that amniotic fluid EPO levels are elevated in diabetic pregnancies prior to labour $[3,4,21]$. In accordance with previous observations, amniotic fluid EPO levels correlated strongly with simultaneously obtained fetal plasma EPO levels in the present study $[4,9,10]$. How EPO reaches amniotic fluid and how long it takes for EPO levels to increase in the amniotic fluid after the fetus becomes hypoxaemic remain to be determined. In experimental models, fetal serum or plasma EPO levels increase 3 to $4 \mathrm{~h}$ after the beginning of moderate to severe hypoxaemia $[26,27]$ and amniotic fluid EPO levels increase $6 \mathrm{~h}$ after [27]. These observations suggest that a minimum of several hours of fetal hypoxia is needed before EPO levels increase in the amniotic fluid.

It has been shown in fetal sheep during glucose infusion that when arterial oxygen content falls below $60 \%$ of basal levels, fetal arterial plasma EPO levels start to rapidly increase [19]. Although arterial oxygen content is a more sensitive indicator of tissue oxygenation than arterial $\mathrm{pO}_{2}$ [28], a similar relationship was observed in the present study between umbilical artery $\mathrm{pO}_{2}$ and amniotic fluid EPO levels: amniotic fluid EPO levels correlated inversely and exponential- ly with umbilical artery $\mathrm{pO}_{2}$ levels below $2.0 \mathrm{kPa}$ $(<15.0 \mathrm{~mm} \mathrm{Hg})$ at birth (Fig. 1b).

Repeated amniotic fluid EPO measurements showed sharply increasing EPO levels in all 6 cases with high amniotic fluid EPO concentration. Similar increases in amniotic fluid EPO levels have also been observed in pregnancies complicated by hypertension [29] and by severe Rh-immunisation [8]. The rapid increase in amniotic fluid EPO concentration suggests that fetal hypoxia, irrespective of aetiology, results in marked increase in fetal EPO synthesis with the likely effect of increasing fetal oxygen-carrying capacity by increasing fetal erythrocyte production. This sharp increase in fetal EPO levels may also have a different purpose. Recent experimental [30, 31] and clinical studies [32] indicate that EPO also has a neuroprotective function in the brain. It has been shown in human adults that, following i. v. administration, recombinant EPO can cross the blood-brain barrier, producing a 60 - to 100-fold increase in cerebrospinal fluid EPO levels [32]. Whether this occurs also in the fetus is not known.

Measurement of amniotic fluid EPO levels would be a novel way of identifing fetuses with chronic hypoxaemia and increased risk of severe neonatal complications, particularly hypoglycaemia and hypertrophic cardiomyopathy, in Type 1 diabetic pregnancies. In the present study, repeated measurements of amniotic fluid EPO levels showed that EPO concentrations increased sharply in cases with elevated amniotic fluid EPO levels. In the three cases in which high EPO levels were not known before delivery, EPO levels increased above normal levels several days before fetal heart rate changes were observed. Thus, increased amniotic fluid EPO levels would have warned of imminent fetal distress in these cases. Fetal lung maturity measurements from amniotic fluid would help in the decision of whether to deliver the fetus with a high amniotic fluid EPO level.

Future research. Future studies should investigate the site and the mechanisms controlling the increased EPO synthesis in hypoxaemic fetuses. Another important field of research is the possible neuroprotective role of EPO in the fetus. Further studies are also needed to evaluate the clinical usefulness of antenatal amniotic fluid EPO measurements in diabetic and other high-risk pregnancies.

\section{References}

1. Mimouni F, Miodovnik M, Siddiqi TA, Khoury J, Tsang RC (1988) Perinatal asphyxia in infants of insulin-dependent diabetic mothers. J Pediatr 113:345-353

2. Salvesen DR, Brudenell JM, Snijders RJM, Ireland RM, Nicolaides KH (1993) Fetal plasma erythropoietin in pregnancies complicated by maternal diabetes mellitus. Am J Obstet Gynecol 168:88-94 
3. Widness JA, Susa JB, Garcia JF et al. (1981) Increased erythropoiesis and elevated erythropoietin in infants born to diabetic mothers and hyperinsulinemic rhesus fetuses. J Clin Invest 67:637-642

4. Teramo KA, Widness JA, Clemons GK, Voutilainen P, McKinlay S, Schwartz R (1987) Amniotic fluid erythropoietin correlates with umbilical plasma erythropoietin in normal and abnormal pregnancy. Obstet Gynecol 69:710-716

5. Mimouni F, Miodovnik M, Siddiqi TA, Butler JB, Holroyde J, Tsang R (1986) Neonatal polycythemia in infants of insulin-dependent diabetic mothers. Obstet Gynecol 68:370-372

6. Cordero L, Treuer SH, Landon MB, Gabbe SG (1998) Management of infants of diabetic mothers. Arch Pediatr Adolesc Med 152:249-254

7. Petry CD, Eaton MA, Wobken JD, Mills MM, Johnson DE, Georgieff MK (1992) Iron deficiency of liver, heart, and brain in newborn infants of diabetic mothers. J Pediatr 121:109-114

8. Voutilainen PEJ, Widness JA, Clemons GK, Schwartz R, Teramo KA (1989) Amniotic fluid erythropoietin predicts fetal distress in Rh-immunized pregnancies. Am J Obstet Gynecol 160:429-434

9. Westgren M, Ek S, Remberger M, Ringden O, Stangenberg M (1995) Cytokine in fetal blood and amniotic fluid in Rh-immunized pregnancies. Obstet Gynecol 86:209-213

10. Buescher U, Hertwig K, Wolf C, Dudenhausen JW (1998) Erythropoietin in amniotic fluid as a marker of chronic fetal hypoxia. Int J Gynecol Obstet 60:257-263

11. Widness JA, Schmidt RL, Sawyer ST (1995) Erythropoietin transplacental passage-review of animal studies. J Perinat Med 23:61-70

12. Maier RF, Böhme K, Dudenhausen JW, Obladen M (1993) Cord blood erythropoietin in relation to different markers of fetal hypoxia. Obstet Gynecol 81:575-580

13. Rollins MD, Maxwell AP, Afrasiabi M, Halliday HL, Lappin TRJ (1993) Cord blood erythropoietin, $\mathrm{pH}, \mathrm{PaO}_{2}$ and haematocrit following caesarean section before labour. Biol Neonate 63:147-152

14. Widness JA, Clemons GK, Garcia JF, Oh W, Schwartz R (1984) Increased immunoreactive erythropoietin in cord serum after labor. Am J Obstet Gynecol 148:194-197

15. Pihkala J, Hakala T, Voutilainen P, Raivio K (1989) New Finnish fetal growth curves [article in Finnish]. Duodecim 105:1540-1546

16. Allan L (2000) M-mode echocardiography. In: Allan L, Hornberger L, Sharland G (eds) Textbook of fetal cardiology, 1st edn. Greenwich Medical Media, London, pp 95-102

17. Madsen H (1986) Fetal oxygenation in diabetic pregnancy. Danish Med Bull 33:64-74
18. Carson BS, Philipps AF, Simmons MA, Battaglia FC, Meschia G (1980) The effects of sustained insulin infusion upon glucose uptake and oxygenation in the ovine fetus. Pediatr Res 14:147-152

19. Philipps AF, Widness JA, Garcia JF, Raye JR, Schwartz R (1982) Erythropoietin elevation in the chronically hyperglycemic fetal lamb. Proc Soc Exp Biol Med 170:42-47

20. Milley JR, Rosenberg AA, Philipps AF, Molteni RA, Jones MD, Simmons MA (1984) The effect of insulin on ovine fetal oxygen extraction. Am J Obstet Gynecol 149:673-678

21. Widness JA, Teramo KA, Clemons GK et al. (1990) Direct relationship of antepartum glucose control and fetal erythropoietin in human Type 1(insulin-dependent) diabetic pregnancy. Diabetologia 33:378-383

22. Hagbard L (1956) Pregnancy and diabetes mellitus; a clinical study. Acta Obstet Gynecol Scand 35 [Suppl 1]:1-180

23. Lauenborg J, Mathiesen E, Ovesen P et al. (2003) Audit on stillbirths in women with pregestational Type 1 diabetes. Diabetes Care 26:1385-1389

24. Casson IF, Clarke CA, Howard CV et al. (1997) Outcomes of pregnancy in insulin dependent diabetic women: results of a five year population cohort study. BMJ 315:275278

25. Kjos SL, Leung A, Henry OA, Victor MR, Paul RH, Medearis AL (1995) Antepartum surveillance in diabetic pregnancies: predictors of fetal distress in labor. Am J Obstet Gynecol 173:1532-1539

26. Widness JA, Teramo KA, Clemons GK et al. (1986) Temporal response of immunoreactive erythropoietin to acute hypoxemia in fetal sheep. Pediatr Res 20:15-19

27. Kakuya F, Shirai M, Takase M, Ishii N, Okuno A (1997) Effect of hypoxia on amniotic fluid erythropoietin levels in fetal rats. Biol Neonate 72:118-124

28. Meschia G (1979) Supply of oxygen to the fetus. J Reprod Med 23:160-165

29. Teramo KA, Hiilesmaa VK, Schwartz R, Clemons GK, Widness JA (2004) Amniotic fluid and cord plasma erythropoietin levels in pregnancies complicated by preeclampsia, pregnancy-induced hypertension and chronic hypertension. J Perinat Med 32:240-247

30. Chong ZZ, Kang JQ, Maiese K (2002) Hematopoietic factor erythropoietin fosters neuroprotection through novel signal transduction cascades. J Cereb Blood Flow Metab 22:503-514

31. Sirén AL, Fratelli M, Goemans C et al. (2001) Erythropoietin prevents neuronal apoptosis after cerebral ischemia and metabolic stress. Proc Natl Acad Sci USA 98:4044-4049

32. Ehrenreich H, Hasselblatt M, Dembowski C et al. (2002) Erythropoietin therapy for acute stroke is both safe and beneficial. Mol Med 8:495-505 